\title{
Keratopustular variety of framboesiform syphilis: A case report
}

\author{
K. LEJMAN AND Z. STARZYCKI \\ From the Dermatological Clinic, Medical Academy, Kraków, Poland
}

SUMMARY An unusual form of secondary syphilis is presented, characterised by eruption of keratopustular syphilides which became confluent on the genitals and on other surfaces of the body. Histologically an intensive intraepidermal multilocular pustule formation was followed by equally intense but incomplete keratinisation. Abundant oozing lesions forced the patient to keep the genitals in a plastic bag which led to the formation of an uncommon, giant condylomatous surface covering the scrotum and penis.

\section{Introduction}

A review of the literature on syphilis from the turn of the nineteenth century leads to the conclusion that early syphilis of that time showed different variants of secondary eruptions, scarcely seen today. However, even contemporary syphilis may assume an unusual clinical appearance as in the case presented below.

\section{Case report}

A 33-year-old divorced man, a seasonal worker, admitted multiple casual sexual contacts with different women. Three months earlier, an ulcer had appeared on the dorsal surface of the penis, followed by inflammatory phimosis and moderate bilateral enlargement of inguinal lymph nodes. A month before an eruption had developed involving the trunk, extremities, and genitals. The lesions enlarged gradually covering the whole scrotum and the skin of the penis: on the penis they oozed, moistening the underclothes and even the trousers of the patient. To prevent this, he kept his genitals in a plastic bag bound with string. Although the exudation worsened the patient succeeded in protecting his clothes. Three weeks before admission to the clinic he became hoarse.

$\mathrm{He}$ had been treated for gonorrhoea 10 years

Address for reprints: Professor K. Lejman, Klinika Dermatologiczna AM, ul. Kopernika 17, 31-501 Kraków, Poland

Received for publication 25 January 1977 previously. Apart from this, he gave no history of any serious illness.

\section{EXAMINATION}

The patient was of medium size and well nourished. His weight was $62 \mathrm{~kg}$. On the trunk, limbs, neck, and face there was an infiltrated, flattened papular eruption on a slightly erythematous base, covered with cracked scales giving a verrucous surface. The diameter of the lesions varied from 2 to $15 \mathrm{~mm}$; the largest were on the thighs below the groin, and showed polycyclic borders after coalesence of smaller papules resembling 'dried' condylomatous lesions (Figs 1 and 2). Scraping the scales was followed by a profuse oozing of the denuded surface.

The skin of the scrotum and penis was heavily infiltrated, resembling a giant, uniform condylomatous lesion and showing exactly the same surface features as the lesions on the thighs and elsewhere except that immediately after the plastic bag covering the genitals had been removed, they were macerated and oozing. The prepuce was not retractable.

The perineal region, palms, and soles were free from lesions. Ulcerative pharyngitis and general moderate enlargement of lymph nodes completed the clinical picture. It is noteworthy that the inguinal lymph nodes were only moderately enlarged.

\section{LA BORATORY INVESTIGATIONS}

Dark-field examination of the serum squeezed from the papules and scrotal wall after the scales had been mechanically removed revealed typical, numerous 


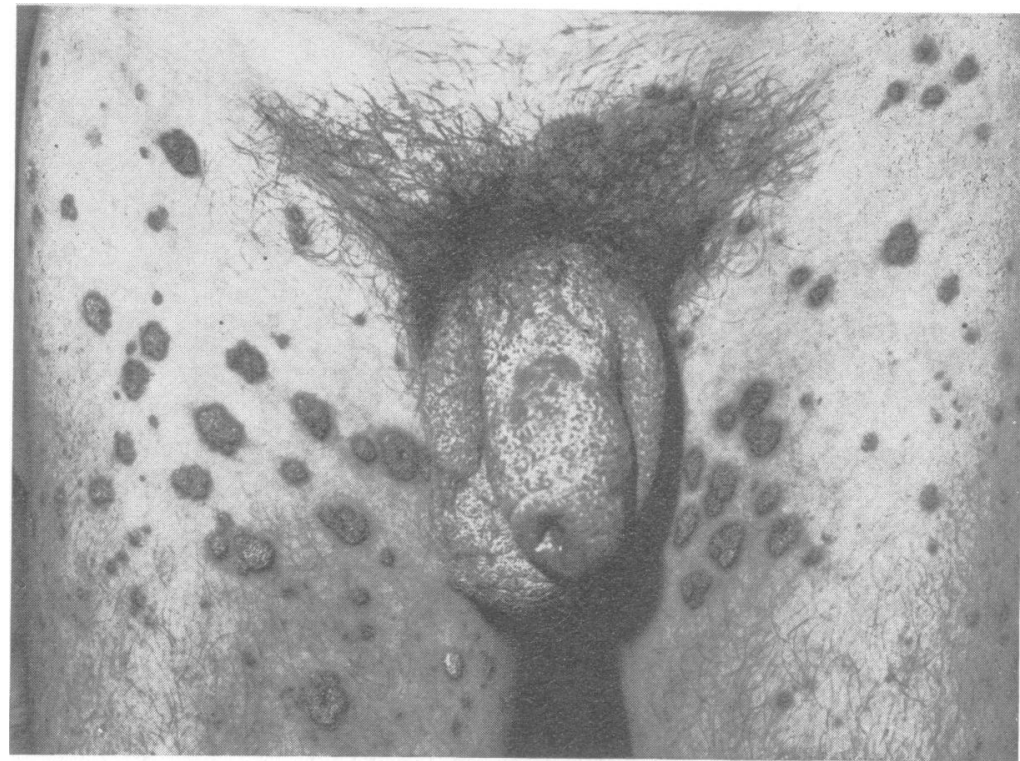

Fig. 1 Eruption of keratopustular variety of framboesiform syphiiis on thighs. Confluent condylomatous lesion on the genitals caused by keeping them in a plastic bag.

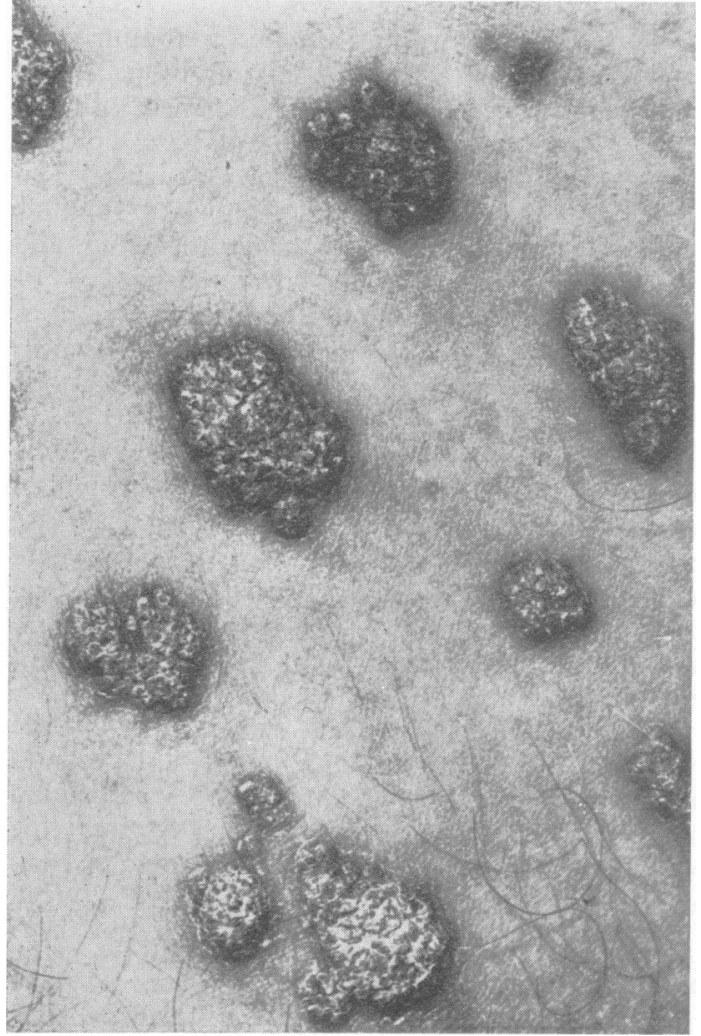

Fig. 2 Detail of Fig. 1.
Treponema pallidum without concomitant saprophytic treponemes.

Haemoglobin $11.9 \mathrm{~g} / \mathrm{dl}$, erythrocyte sedimentation rate $53 \mathrm{~mm} / \mathrm{h}$, WBC $5.5 \times 10^{\%} / 1$, with a normal differential. Urine analysis was normal.

The serum Wassermann reaction (WR) was strongly positive, the Venereal Diseases Reference Laboratory (VDRL) test reactive at $1: 64$, the $T$. pallidum immobilisation (TPI) test was positive with $100 \%$ immobilisation, the fluorescent treponemal antibody (FTA-200) test was reactive at a titre of $1: 108 \cdot 000$.

The cerebrospinal fluid and cell count were normal. The WR, VDRL, and TPI tests were negative; FTA was positive at a titre $1: 50$.

\section{Histopathology}

A small papule from the infrascapular region was excised and then divided into two parts: one for routine histopathological procedures, the other for silver impregnation using a modified Krajian's method (Walter et al., 1969).

Examination of the sections stained with haematoxylin and eosin allowed assessment of the development of the lesions. Massive migration of neutrophils towards the epidermis from the capillaries in the adjacent papillae of the skin had led to disruption and delamination of the spinous layer thus forming spongiform pustules (Fig. 3). In the stages that followed these pustules had undergone an intense but incomplete keratinisation; the shrunken leuco- 


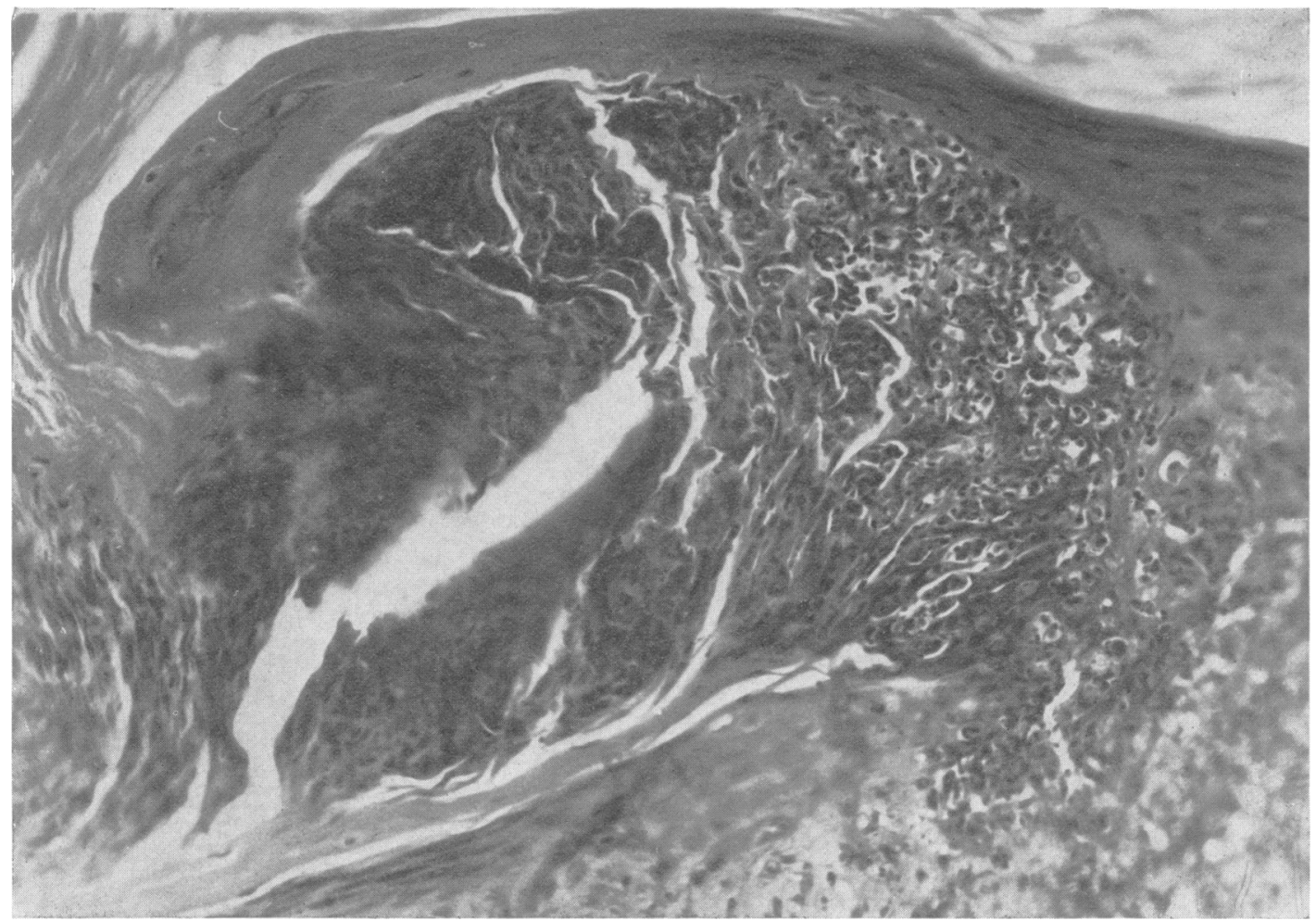

Fig. 3 The intramalpighian spongiform pustule formation. Haematoxylin and eosin $\times 240$.

cytes were intermingled with parakeratotic masses thus forming the 'keratopustular' scales, surrounded on the outside by parakeratotic or even hyperkeratotic layers (Fig. 4). On the surface of the lesion the loosely adherent keratopustular scales had undergone desquamation. The papillary and subpapillary layers were intensively infiltrated predominantly by plasma cells; the blood vessels showed thickened walls and were in places filled with thrombi; in the dermis under the infiltrate and near the lesions the blood vessels were dilated and filled with leucocytes and erythrocytes.

In sections stained using a modified version of Krajian's method, multiple $T$. pallidum were situated between the cells of dermal infiltrate (Fig. 5) and in the walls of the blood vessels. Within the epidermis the treponemes were scarce.

Even in the small papule biopsed from the infrascapular region there was a marked tendency for the dermo-epidermal border to form a verrucous shape. It was expected that the main histopathological features of the papule - that is, para- and hyperkeratosis, the formation of intraepidermal pustule, and a tendency to the verrucosity-would be more marked in the lesions on the thighs. The same was true of the giant lesion covering the genitals, which showed exactly the same superficial features as the disseminated lesions. Unfortunately the patient did not give his consent to the biopsy from this region.

\section{Differential diagnosis and discussion}

The diagnosis of secondary syphilis in our case was unquestionable. However, there were difficulties in classifying its clinical form. Skin lesions did not correspond clinically and histopathologically with papulosquamous syphilides, particularly as the palms and soles of our patient were completely free of such lesions.

Clinical and histopathological characteristics of our case should be discussed especially in relation to framboesiform syphilis, an entity seldom seen today. In the contemporary textbooks on syphilis, as well as in older reports, its classification has not been precisely established. Descriptions range from vegetating, nodular, or even tumorous form with abundant foul secretion (Kaposi, 1891) to the 


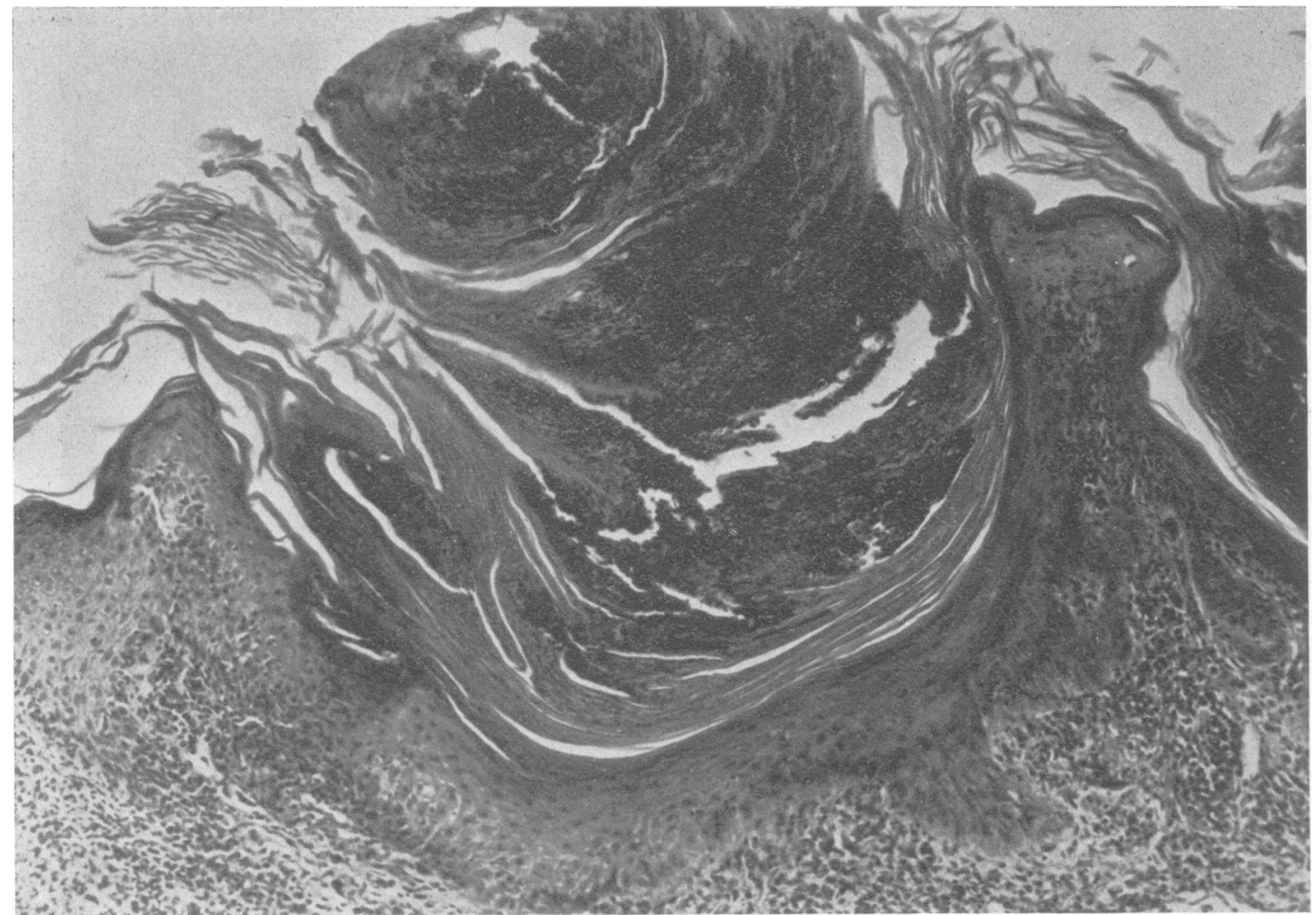

Fig. 4 Final stage of involution of the intramalpighian spongiform pustule: thick keratopustular scale. Haematoxylin and eosin $\times 160$.

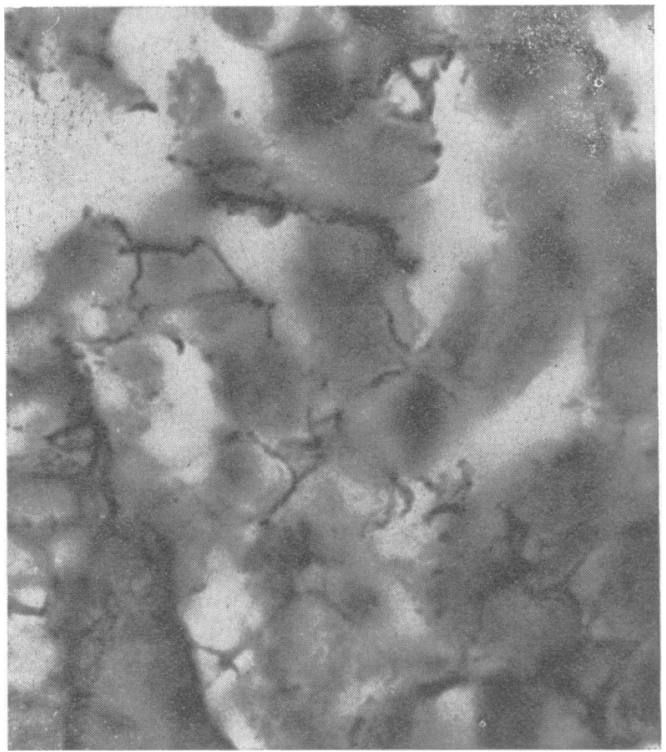

Fig. 5 Treponemes between the cells of the dermal infiltrate. Modified Krajian silver stain $\times 1 \cdot 200$. 'syphilis cutanea verrucosa' (Demjanovitsch, 1915) and 'framboesiform papules or syphilis cutanea vegetans' (Finger, 1930). The appearance of the lesions of framboesiform syphilis may vary from being scarce, ulcerated, raspberry-like lesions as in the case of Merian (1911), to the abundant papular eruption composed of lesions with a keratotic and verrucous surface (Demjanovitsch, 1915). Krüger (1965) emphasised that ulceration, vegetation, and crust formation were the main clinical features of framboesiform syphilis (especially of the scalp).

Although our case seems to correspond with the clinical features of framboesiform syphilis, as depicted by the above authors, there is an important difference. None of the authors emphasises the intense pustulation of syphilides with their subsequent vivid but incomplete keratinisation.

It seems that the results of clinical and histopathological investigations of this case justify the diagnosis of a peculiar keratopustular variety of framboesiform syphilis.

By keeping his genitals in a plastic bag, the patient created a microaerophilic, humid, warm milieu, encouraging the treponemal infection in this region 
leading to confluence of the oozing lesions into an uncommon, giant condylomatous surface.

The diagnosis of yaws in our patient was out of the question as yaws has never been recorded in Poland and the patient had never been abroad.

\section{Treatment and course of illness}

The patient was given intramuscular procaine penicillin 900000 units daily to a total dose of 24 megaunits (the last injection was increased to 1500000 units). Six hours after the first injection, the patient's temperature rose to $37 \cdot 8^{\circ} \mathrm{C}$.

At the end of the treatment the lesions on the trunk and extremities resorbed almost completely, leaving pigmented patches. The scrotal skin returned to nearly its normal appearance. The VDRL titre fell from $1: 64$ to $1: 8$. The patient failed to return later, despite several requests.

\section{References}

Demjanovitsch, M. (1915). Uber eine seltene Form von sekundärer Lues (syphilis cutanea verrucosa). Dermatologische Zeitschrift, 20, 212-220.

Finger, E. (1930). Generalisierte Syphilis der Haut und der Mundund Rachenhöhle. In Handbuch Haut Geschlechtskr, 16/1, 205. Edited by J. Jadassohn. Springer: Berlin.

Kaposi, M. (1891). Syphilis cutanea vegetans s. papillomatosa. In Pathologie und Therapie der Syphilis, pp.180-181. Enke: Stuttgart.

Krüger, G. H. (1965). Klinik der erworbenen Syphilis (Syphilis I und II). In Dermatologie und Venerologie, 5/2, 906. Edited by $\mathbf{H}$. A. Gottron and W. Schönfeld. Thième: Stuttgart.

Merian, L. (1911). Ein Fall von framboesiformer Syphilis. Monatshefte für praktische Dermatologie, 52, 557-564.

Walter, E. K., Smith, J. Lawton, Israel, C. W., and Gager, W. E. (1969). A new modification of the Krajian silver stain for Treponema pallidum. British Journal of Venereal Diseases, 45, 6-9. 